\title{
Brigada Estudantil de Prevenção de Acidentese Primeiros Socorros em Palmas (TO)
}

\section{Accident Prevention and First Aid Student Brigade in Palmas (TO)}

\author{
Luiza Lelis Neves Limal \\ Reinaldo Neves Junior ${ }^{I}$
}

\section{PALAVRAS-CHAVE}

- Internato e Residência;

- Urgência e emergência;

- Medicina;

- Educação Médica.

\section{KEYWORDS}

- Internship and Residency;

- Urgency and emergency;

- Medicine;

- Medical Education.
Recebido em:30/09/2014

Aprovado em: 15/02/2016

\section{RESUMO}

A Universidade Federal do Tocantins, o Samu, as Secretarias Municipais de Saúde e de Educação de Palmas e o Centro Universitário Luterano de Palmas elaboraram, em parceria, uma proposta de ações de prevenção de acidentes e primeiros socorros direcionada às escolas do município, a fim de preparar a comunidade escolar para lidar com situações adversas e acidentes. A equipe do Samu e das secretarias realizou a capacitação no Módulo de Urgências e Emergências dos acadêmicos do curso de Medicina da Universidade Federal do Tocantins (UFT), do internato e também da Liga Universitária Tocantinense de Trauma (Lutte) e dos acadêmicos de Enfermagem da Ulbra para que seus integrantes ministrassem palestras aos funcionários das escolas da rede municipal. A Brigada apresentou resultados positivos quanto à aceitação e à satisfação dos funcionários das escolas, que tiveram a oportunidade de tirar suas dúvidas sobre situações rotineiras vivenciadas tanto por alunos quanto por eles próprios nas escolas. A experiência foi também enriquecedora para os acadêmicos, que tiveram a oportunidade de exercer sua cidadania, contribuindo para o bem-estar da sociedade e para a promoção da saúde.

\section{ABSTRACT}

The Federal University of Tocantins in partnership with the Mobile Emergency Medical Services (SAMU), the Palmas Municipal Health and Education Departments and the Lutheran University of Palmas, drew up a proposal aimed at local schools for accident prevention and first aid in order to prepare the school community to deal with adverse situations and accidents. Staff from the SAMU and the municipal departments, trained medicine students, interns and nursing students from three schools in, emergency care for them to give lectures to the staff of municipal schools. The Brigade showed positive results regarding the acceptance and satisfaction among the school employees, who had the opportunity to resolve their doubts about everyday situations experienced both by students and by school staff. The experience was also rewarding for the students, who had the opportunity to exercise their citizenship, contributing to the welfare of society and health promotion. 


\section{INTRODUÇÃO}

A Organização das Nações Unidas (ONU) fundamenta que o conceito de segurança humana deve estar centrado no desenvolvimento do ser humano, abrangendo a segurança de todos os cidadãos no seu cotidiano: nas vias públicas, no trabalho, na escola, no lazer e no lar. O Estado continua a ser o principal responsável pela segurança. No entanto, a partir do momento em que os problemas de segurança aumentam em complexidade, novos atores passam a desempenhar um papel nesse domínio. Assim, outros setores da sociedade emergem como determinantes do estado de segurança. Entre eles, destacam-se a saúde e a educação ${ }^{1}$.

Diversas conferências internacionais na área de saúde defendem a ideia de promoção como um paradigma alternativo para as políticas de saúde em todos os países. Os compromissos e as orientações que servem de base para a promoção da saúde e da educação em saúde no âmbito escolar, segundo Ippolito-Shepherd (2002), foram definidos em eventos que produziram os seguintes documentos: Carta de Ottawa (1986), Declaração de Adelaide (1988), Declaração de Sundsvall (1991), Declaração de Bogotá (1992), Conferência do Caribe (1993), Declaração de Jacarta (1997) e Declaração do México $(2000)^{2} \cdot(p .495)$

Na Carta de Ottawa, resultado da I Conferência Internacional de Promoção de Saúde, a promoção de saúde é definida como um:

[...] processo destinado a capacitar os indivíduos para exercerem um maior controle sobre sua saúde e sobre os fatores que podem afetá-la [...], reduzindo os fatores que podem resultar em risco e favorecendo os que são protetores e saudáveis [...] a saúde desenvolve-se e é gerada no marco da vida cotidiana: nos centros de ensino, de trabalho e de recreação. A saúde é o resultado dos cuidados que cada indivíduo dispensa a si mesmo e aos demais, da capacidade de tomar decisões, de controlar sua própria vida e de garantir que a sociedade em que vive ofereça a todos os seus membros a possibilidade de gozar de um bom estado de saúde. (p.495)

A promoção da saúde vai além de um estilo de vida saudável; caminha em direção a um bem-estar global, individual e coletivo em todos os níveis. Trabalhar a questão da segurança vem ao encontro da proposta da promoção de saúde ${ }^{1}$.

A promoção da saúde é considerada uma combinação de apoios educacionais e ambientais que visam atingir ações e condições de vida conducentes à saúde. Desde o final do sé- culo passado, ela representa uma estratégia para enfrentar os múltiplos problemas de saúde que afetam as populações humanas e seus entornos. Para o processo saúde-doença, a promoção da saúde propõe a articulação entre saberes técnicos e saberes populares, além da mobilização de recursos institucionais e comunitários, públicos e privados².

O segmento representado por crianças e adolescentes possui seus direitos garantidos por lei a partir do Estatuto da Criança e do Adolescente ${ }^{3}$. Atualmente, observa-se uma preocupação das instituições públicas e privadas em garantir esses direitos e, em especial, com as questões relacionadas a acidentes e violências ocorridos na infância. Essa preocupação se deve ao fato de que os índices de acidentes e violências vêm aumentando e tornando-se um grave problema de saúde pública ${ }^{4}$.

Os acidentes e violências consistem em um conjunto de agravos à saúde que podem levar ao óbito ou não, nos quais estão inseridas as causas acidentais (por trânsito, quedas, afogamentos, entre outros) e as intencionais (agressões e lesões autoprovocadas).Este conjunto de eventos é denominado causas externas. Em 2005, no Brasil, o total de óbitos da população de faixa etária entre menor de um ano e 19 anos, segundo causas externas, foi de 21.040 , o que representa $23,42 \%$ do total de óbitos neste grupo. Neste sentido, as escolas têm um papel importante e crescente na promoção de saúde e na prevenção de doenças e de acidentes entre crianças e adolescentes ${ }^{4}$.

Na Argentina, o Ministério do Desenvolvimento Social e da Saúde, junto com a Diretoria Geral das Escolas, vem desenvolvendo, desde o ano 2000, o projeto "Escola Segura e Saudável", com o objetivo de diminuir o número de acidentes infantis nas escolas, em casa e em vias públicas, por meio de medidas de integração entre comunidade, alunos, professores e demais funcionários das escolas, gerando condutas de autopreservação e respeito ${ }^{1}$.

No Brasil, há exemplos de estratégias implementadas pela sociedade civil e pelas várias esferas do governo com vistas à redução de acidentes e violências. O Ministério da Saúde destaca a importância do período escolar para a abordagem da saúde na perspectiva de sua promoção, por intermédio do desenvolvimento de ações para a prevenção de doenças e para o fortalecimento dos fatores de proteção. A escola possui uma função social e política voltada à transformação da sociedade e ao exercício da cidadania, o que justifica o desenvolvimento de ações de promoção da saúde voltadas para a comunidade escolar.

Membros da Sociedade Brasileira de Pediatria (SBP), preocupados com os altos índices de mortalidade por causas externas entre crianças e adolescentes, iniciaram em outubro de 1998 a "Campanha Nacional de Prevenção de Acidentes e 
contra a Violência na Infância e Adolescência". Outra grande conquista nessa área foi obtida em Recife (PE), com a aprovação, em 2001, do projeto de lei para instalação das comissões internas de prevenção de acidentes e violência nas escolas (Cipave). Com o objetivo de instruir alunos e sociedade, o Corpo de Bombeiros Militar de Pernambuco (CBMPE) também atua em ações educativas. Desde 2003, atividades como teatro de fantoches, exposições e palestras sobre primeiros socorros, prevenção de acidentes, higiene bucal, entre outras, vêm sendo desenvolvidas por meio de parcerias com a Secretaria Estadual de Saúde, Secretaria de Defesa Social e organizações não governamentais ${ }^{1}$.

A Universidade Federal do Tocantins, em parceria com o Samu, com as Secretarias Municipais de Saúde e de Educação de Palmas e com o Centro Universitário Luterano de Palmas, elaborou uma proposta de ações de prevenção de acidentes e primeiros socorros direcionada às escolas do município, a fim de preparar a comunidade escolar para lidar com situações adversas e acidentes. A iniciativa foi denominada Brigada Estudantil.

\section{OBJETIVO}

Promover a capacitação, realizada pela equipe do Samu e das secretarias, dos acadêmicos do curso de Medicina da UFT, no Módulo de Urgências e Emergências do internato e também da Liga Universitária Tocantinense de Trauma (Lutte) e dos acadêmicos de Enfermagem da Ulbra para que eles ministrem palestras aos funcionários das escolas da rede municipal de Palmas (TO).

\section{RELATO DE EXPERIÊNCIA}

As atividades da Brigada tiveram início em 27 de maio de 2013 com a capacitação dos acadêmicos pelas equipes das Secretarias Municipais de Saúde e de Educação e também pela equipe do Samu. Tal capacitação consistiu em palestras sobre prevenção e promoção da saúde, e contou também com aulas teóricas e práticas de primeiros socorros.

Ao longo de 20 dias, os grupos formados por internos e acadêmicos do curso de Medicina da UFT e por acadêmicos do curso de Enfermagem da Ulbra, juntamente com um profissional da Secretaria de Saúde, ministraram palestras nas escolas municipais de Palmas. O público-alvo foi constituído pelos funcionários da escola, incluindo professores, técnico-administrativos, assistentes de serviços gerais, merendeiras e vigias. Os grupos foram divididos de acordo com as disponibilidades de horário e de modo a garantir a conciliação com as atividades acadêmicas. Os locais em que cada grupo atuou foram distribuídos por sorteio.
As palestras ocorreram nos períodos matutino e vespertino e tiveram a duração média de 4 horas por apresentação. Foi utilizada uma metodologia participativa, por meio da multiplicação de informações, desenvolvendo o engajamento da população-alvo como sujeitos coletivos na melhoria da qualidade de vida. As palestras dividiam-se em três momentos: introdução e apresentação de dados epidemiológicos acerca do município de Palmas; prevenção de acidentes e promoção de saúde; primeiros socorros. Foram abordados temas como determinantes de saúde, acidentes de trabalho, saúde vocal, fluxo de atendimento da rede de urgência, primeiros socorros e condutas diante dos principais acidentes e diante de casos de violência. Foram utilizados também bonecos cedidos pelo SAMU para a simulação das manobras de ressuscitação cardíaca.

\section{RESULTADOS E CONCLUSÕES}

Considera-se que, para alcançar a meta de Saúde para todos, não basta desenvolver a atenção primária, mas também uma educação voltada às necessidades e possibilidades da comunidade. A prática médica contemporânea reconhece que, para melhorar o panorama da Saúde Pública, é necessário educar as grandes massas, com o objetivo de promover campanhas em prol da saúde e em detrimento das doenças tributárias de prevenção e controle, por meio de medidas educativas e sanitárias. Como exemplos dessas medidas, podem ser citadas ações como eliminação de mosquitos, desratização, estímulo ao consumo de água potável, campanhas de incentivo às mudanças de hábitos higiênicos e dietéticos, e à realização sistemática de exercícios físicos ${ }^{5}$.

É fundamental esclarecer e treinar a população para o atendimento de situações de emergência que envolvam, por exemplo, a parada cardíaca, evitando a paralisia do socorrista no momento de decidir qual o próximo passo a seguir. A população deve estar capacitada para agir em qualquer situação de emergência, prestando atendimento de primeiros socorros. Assim, de acordo com Pergola e Araújo ${ }^{6}$, os primeiros socorros podem ser definidos "[...] como atendimento imediato providenciado à pessoa doente ou ferida e que pode ser realizado pela população em geral"' (p. 770)

Esses autores também explicam que, em situações de emergência, a avaliação da vítima e seu atendimento devem ser realizados de forma rápida, objetiva e eficaz, proporcionando às vítimas aumento da sobrevida e redução de sequelas. Nesse sentido, eles definem que "O suporte básico à vida (SBV) inclui etapas de socorro à vítima em situação de emergência que represente risco à vida e, em sua maioria, esse atendimento pode ser iniciado no ambiente pré-hospitalar" ${ }^{\prime \prime}(p .770)$ 
As mortes e traumas decorrentes de violências e acidentes aumentam de maneira absoluta em todo o globo, demandando uma resposta rápida e organizada do sistema. Essas causas incidem em um grupo particularmente vulnerável: os jovens e as crianças. $\mathrm{O}$ ambiente escolar representa uma importante faceta desse problema, que é multifatorial, a partir do momento em que crianças e jovens passam grande parte do tempo na escola, onde esses assuntos ligados à saúde devem ser abordados e discutidos ${ }^{1}$.

Nesse sentido, a construção de uma "Escola Segura" constitui uma tarefa complexa. Uma escola onde a preocupação em prevenir acidentes e violências seja uma constante, que estimule hábitos de vida saudável, que garanta boa educação, que estimule todos os alunos sem preconceito, que perceba suas dificuldades e que os prepare para a vida é, sem dúvida, um ideal que devemos perseguir. Toda a esperança e fascínio que a criança tem ao ingressar na escola não podem ser quebrados e destruídos diante das dificuldades observadas nas unidades escolares.

A proposta da Escola Promotora de Saúde serve como base teórica do que devemos fazer para tornar o ambiente escolar o mais seguro possível, propiciando um bom desenvolvimento físico, social, intelectual e cultural a todos. Para isso, é necessária a participação conjunta dos profissionais da saúde e da educação, no sentido de conhecer melhor a temática e atuar de forma mais específica e eficaz na construção da "Escola Segura". Em todas as propostas para a redução de acidentes e violências nas escolas, a discussão e a construção do conhecimento devem ser participativas, envolvendo o corpo docente, os pais e os membros da comunidade, que representam o centro das atividades. Além disso, a abertura das escolas para a comunidade, fomentando a sua participação, foi medida adotada por muitas escolas, objetivando a redução das violências ${ }^{1}$.

A Brigada apresentou resultados positivos quanto à aceitação e à satisfação dos funcionários das escolas, que tiveram a oportunidade de tirar suas dúvidas sobre situações rotineiras vivenciadas tanto por alunos quanto por eles próprios durante o trabalho nas escolas. A experiência foi também enriquecedora para os acadêmicos, que tiveram a oportunidade de exercer sua cidadania, contribuindo para o bem-estar da sociedade e para a promoção da saúde.

\section{REFERÊNCIAS}

1. Liberal EF, Aires RT, Aires MT, Osório ACA. Escola segura.J. Pediatr. 2005;81(5 Supl):155-163.

2. Moura JBVS, LourinhoLA, Valdês MTM, Frota MA, Catrib AMF. Perspectiva da epistemologia histórica e a escola promotora de saúde. Hist. Cienc. saúde-Manguinhos 2007;14(2):489-501.

3. Brasil. Lei 8.069 de 13 jul 1990. Estatuto da Criança e do Adolescente. Dispõe sobre o Estatuto da Criança e do Adolescente e dá outras providências. [on line] Presidência da República. Casa Civil. 13 jul 1990. [capturado em 22 mar 2016] Disponível em: http://www.planalto.gov.br/ccivil_03/leis/L8069.htm

4. Fioruc BE, Molina AC, Vitti Júnior W, Lima SAM. Educação em saúde: abordando primeiros socorros em escolas públicas no interior de São Paulo. Rev. Eletr. Enf. [on line]. 2008 [capturado em 22 mar 2016]; 10(3):695-702. Disponível em: https://www.fen.ufg.br/fen_revista/v10/n3/ pdf/v10n3a15.pdf

5. Rodríguez CA, Kolling MG, Mesquida P. Educação e Saúde: um Binômio que Merece Ser Resgatado. Rev. Bras. Educ. Médica 2007;31(1): 60-66.

6. Pergola AM, Araújo IEM. O leigo em situação de emergência. Rev. Esc. Enferm. 2008; 42(4):769-776.

\section{CONTRIBUIÇÃO DOS AUTORES}

Luiza Lelis Neves Lima - autora.

Pedro Emanuel Gonzalles Cuellar - orientador e co-autor

\section{CONFLITO DE INTERESSES}

Os autores declaram não haver conflito de interesses.

\section{ENDEREÇO PARA CORRESPONDÊNCIA}

Luiza Lelis

Universidade Federal do Tocantins

Avenida NS 15, 109 Norte

Plano Diretor Norte - Palmas

CEP: 77001-090 TO

E-mail: luizalelismed4@gmail.com 